\title{
Peertechz
}

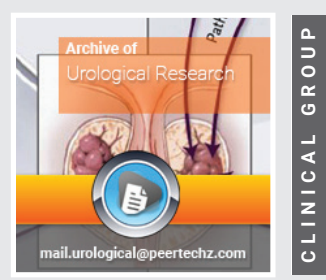

\section{Prenatally diagnosed patent urachus with bladder prolapse: Case Report and review of the literature}

\author{
Stanislaw Warchol ${ }^{1 *}$, Sylwia Slomska², Tomasz \\ Roszkowski $^{2}$ and Teresa Dudek-Warchol ${ }^{1}$ \\ 'Department of Pediatric Surgery and Urology, Medical University of Warsaw, Warsaw, Poland \\ ${ }^{2}$ Department of Obstetrics and Gynecology, Orlowski Public Teaching Hospital, Warsaw, Poland
}

Received: 05 February, 2021

Accepted: 11 February, 2021

Published: 12 February, 2021

*Corresponding authors: Stanislaw Warchol, MD, PhD, Department of Pediatric Surgery and Urology, Medical University of Warsaw, 63A Zwirki \& Wigury street, 02091 Warsaw, Poland, E-mail: swarchol@poczta.onet.pl ORCID: https://orcid.org/0000-0001-9692-8206 Keywords: Patent urachus; Allantoic cyst; Bladder prolapse; Prenatal diagnosis

https://www.peertechz.com

Check for updates

\begin{abstract}
Persistent urachal anomalies are rare congenital lesions of the urinary tract. They result from the failed obliteration of the urachus and are classified according to persistent segment of the urachus. Patent urachus represents complete connection between the bladder and the umbilicus. An unique to newborns form of patent urachus is bladder prolapse inferior to umbilical cord, through the widely patent urachus. This is the least common urachal abnormality, however, because of very characteristic fetal ultrasound picture, can be diagnosed prenatally which allows for the proper treatment after the birth. We report a case of prenatally diagnosed patent urachus with bladder prolapse and its postnatal management. The literature on the subject is enclosed.
\end{abstract}

\section{Introduction}

Persistent urachal anomalies are rare congenital lesions of the urinary tract. These anomalies occur because of the patency of the entire urachus or some portion of it. Patent urachus, which represent complete connection between the bladder and the umbilicus is a very rare anomaly with the reported incidence of 3 per 1000000 live births and is three time more common in males than in females [1-4].

Bladder prolapse through a widely patent urachus, also known as a eversion of the bladder, is the least common urachal abnormality. This entity with distinct fetal and neonatal features was very rarely reported [5-9].

The aim of this report is to present a newborn girl with prenatally diagnosed patent urachus and prolapse of the bladder dome through the umbilicus. Review of the literature on the subject is enclosed.

\section{Case presentation}

In a 26-year-old primigravid women Ultrasound (US) examination at 17 weeks gestational age showed the presence of cystic mass ( $45 \times 30 \mathrm{~mm}$ in diameter) at the base of the umbilical cord, communicating with the urinary bladder (Figure 1). Amniotic fluid volume was normal. At 32-weeks gestation, the cystic mass disappeared and only solid mass inferior to the umbilical cord was detected (Figure 2). No dilatation of the upper urinary tract was noted, the kidneys,

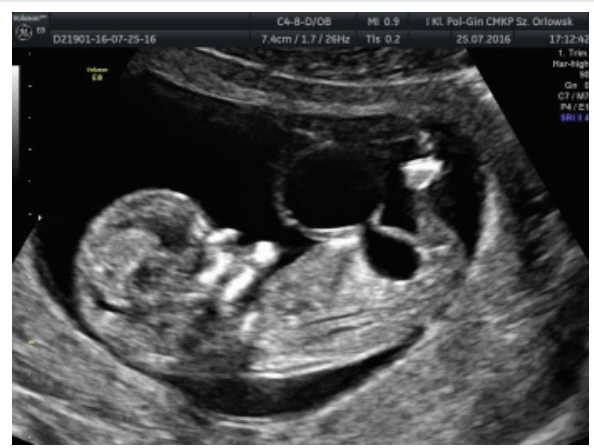

Figure 1: Prenatal US at $17 \mathrm{Hbd}$ : large cystic mass $(45 \times 30 \mathrm{~mm})$ at the base of the umbilical cord, communicating with the urinary bladder.

Citation: Warchol S, Slomska S, Roszkowski T, Dudek-Warchol T (2021) Prenatally diagnosed patent urachus with bladder prolapse: Case Report and review of the literature. Arch Urol Res 5(1): 006-009. DOI: https://dx.doi.org/10.17352/aur.000029 
bladder and amniotic fluid volume were normal. A female newborn was born via vaginal delivery at 39 week of gestation (birth weight $2800 \mathrm{~g}, 9$ Apgar). Immediately after birth because of the presence of red mucosal mass protruding from the umbilicus, the neonatologist diagnosed ruptured umbilical cord hernia. A neonate was transferred to our institution for further treatment (Figure 3). US showed normal upper urinary tract, however, the bladder was not visible. After introduction of Foley catheter into the bladder through the urethra, the tip of the catheter protruded from the umbilicus (Figure 4). Blood urea nitrogen as well as creatinine levels were within normal limits. Cystoscopy revealed elongated bladder with the visible tip of Foley catheter introduced through the umbilicus with normal anatomy of the ureteral orificies, bladder neck and urethra. Contrast study (cystography) showed cylindric shaped, elongated bladder expanding above the umbilicus with contrast leakage throughout the umbilicus (Figure 5). The final diagnosis of bladder prolapse through the patent urachus was established and the patient underwent operative treatment. The widely patent urachus was excised with the prolapsed bladder dome, which was very thin. The bladder was closed in two layers and finally umbilicoplasty was performed (Figure 6). Postoperative period was uneventful. Postoperative US showed normal urinary tract. Voiding cystography performed one month after operation revealed normal shaped bladder with normal bladder volume and no vesico-ureteral reflux. During 3-year follow-up no urinary tract infections as well as no voiding difficulties were observed. Control US performed each 6 months showed normal kidneys, no dilatation of upper urinary tract and bladder volume corresponding to the age of the child. Renal laboratory tests were normal.

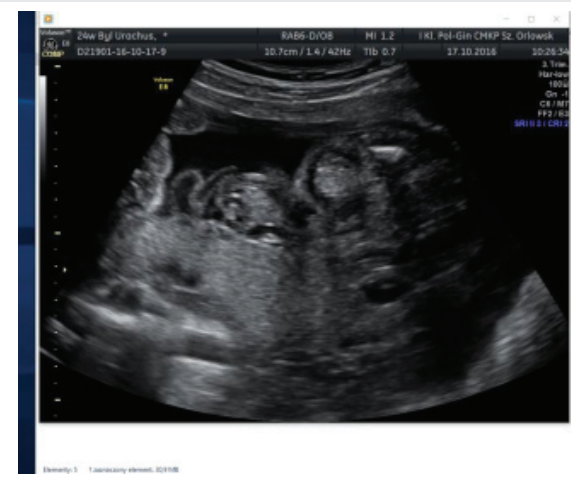

Figure 2: Prenatal US at $32 \mathrm{Hbd}$ : no previous visible cystic mass at the base of the umbilical cord; solid mass inferior to the umbilical cord visible.

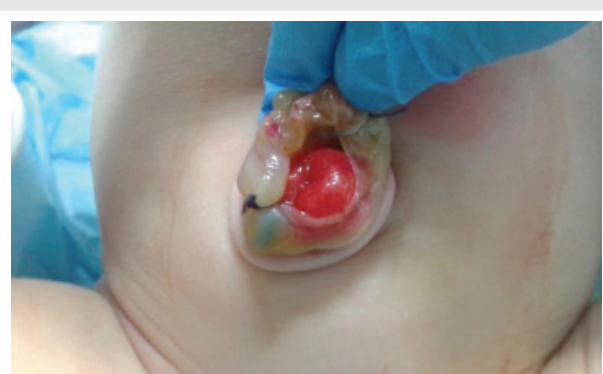

Figure 3: View of the umbilicus immediately after the birth.

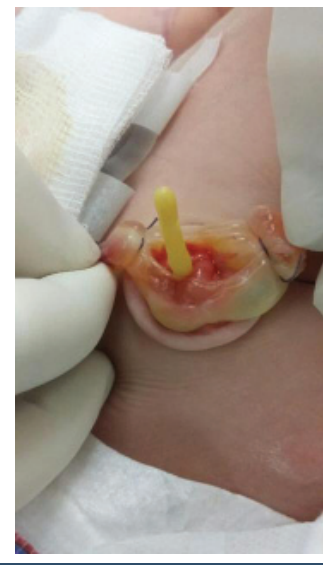

Figure 4: The tip of Foley catheter introduced into the bladder through the urethra protrudes from the umbilicus.

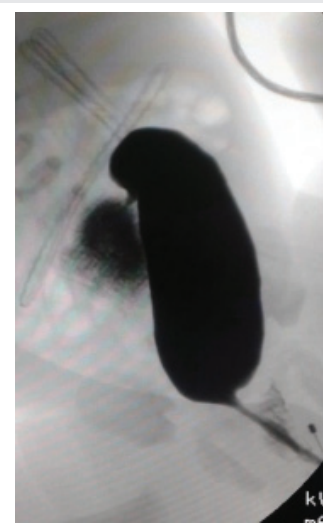

Figure 5: Contrast study (cystography): elongated cylindric-shaped bladder with contrast leak through the umbilicus.

6.a
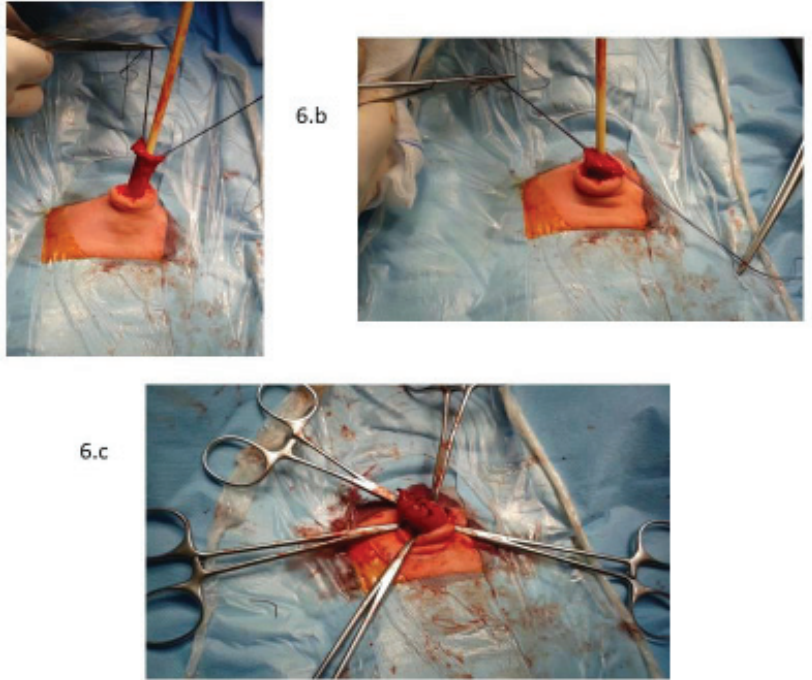

Figure 6: Intraoperative view: resection of the wide patent urachus with bladder dome prolapsed through the umbilicus; bladder closed in layers.

A: view before resection of the urachus

B: view after resection, before closure of the bladder

C: view after bladder closure

\section{Discussion}

The urachus represents the ductal remant of two embryologic structures: the cloaca and the allantois and originates from the

Citation: Warchol S, Slomska S, Roszkowski T, Dudek-Warchol T (2021) Prenatally diagnosed patent urachus with bladder prolapse: Case Report and review of the 
involution of them. The urachus extents between the bladder and the umbilicus. During normal embryological development the urachus involutes and its lumen obliterates, forming the median umbilical ligament.

Urachal anomalies results from the failed obliteration of the urachus and are classified according to the persisting segment usually as: (1) patent urachus connecting the bladder dome to the umbilicus, (2) urachal cysts resulting from failure of obliteration of the medial segment of the urachus, while both the umbilical and bladder ends are obliterated, (3) urachal or umbilical-urachal sinus, when the umbilical end of the urachus fails to obliterate and (4) urachal or vesico-urachal diverticulum caused by an incomplete closure of the bladder end of the urachus [1-4].

Urachal anomalies usually are detected as an abnormalities of the umbilicus in the newborn. Differential diagnosis should include abdominal wall defects (omphalocele, umbilical cord hernia) as well as omphalo-mesenteric duct remants as other possible umbilical anomalies in the neonate. Prompt distinction between the above anomalies followed by proper diagnosis is of utmost importance because of various treatment possibilities. The patent urachus presenting persistent and free communication between the bladder and the umbilicus is most frequently detected by the urinary leakage from the umbilicus, however there have been recently a raising number of reports of the possibility of prenatal diagnosis of the patent urachus [10-14].

A unique form of completely patent urachus is bladder prolapse through it, which may be detected ultrasonographically prenatally. The prenatally recognized ultrasound findings specific to this anomaly are: (1) a cystic mass at the base of umbilical cord separate from the umbilical vessels, (2) communication with the bladder, (3) disappearance of the cyst later in gestation. The cyst usually is found at $14-19$ week of gestation and disappear around gestational week 20 to 32 . It is postulated that disappearance of the cyst is particularly characteristic for the patent urachus with bladder prolapse $[5,6,8,15]$.

We present in this report prenatally diagnosed bladder prolapse through a patent urachus. This anomaly was accurately predicted upon serial fetal ultrasounds. Despite this fact immediately after birth the neonatologist suspected ruptured umbilical cord hernia according to the presence of "mucosal protrusion" within the umbilicus. In the literature one can find reports of patent urachus with bladder eversion or evagination of the bladder, mimicking a spectrum of recognition from ruptured omphalocele to bladder extrophy $[7,8,9,16]$.

The recommended surgical approach for all urachal anomalies is the complete excision of the urachal remant $[1,3,4]$. The described management of patent urachus with bladder eversion consists of mobilization of the bladder, reduction of the prolapse with the resection of the patent urachus and resection of the bladder dome if required, followed by primary closure of the bladder [5-7]. The same operative technique was applied in presented case, using small, periumbilical approach.

\section{Conclusion}

Patent urachus as well as its unique form with bladder prolapse can be accurately diagnosed prenatally and managed properly after birth. Operative treatment including resection of the patent urachus and the prolapsed bladder dome, followed by primary closure of the bladder, provides excellent outcome.

\section{References}

1. Frimberger DC, Kropp BP (2012) Bladder anomalies in children. In . Wein AJ, Kavoussi LR, Novick AC, Partin AW, Peters CA editors. Campbell-Walsh Urology $10^{\text {th }}$ Edition, Elsevier 3379-3388.

2. Villavicencio CP, Adam SZ, Nikolaidis P, Yaghmai V, Miller FH (2016) Imaging of the urachus: anomalies, complications and mimics. Radiographics 36 : 2049-2063. Link: https://bit.ly/3rzvw9k

3. McCollum MO, MacNeily AE, Blair GK (2003) Surgical implications of urachal remants: presentation and management. J Pediatr Surg 38: 798-803. Link: https://bit.ly/373vHSj

4. Ueno T, Hashimoto H, Yokoyama H, Ito M,Kouda K, et al. (2003) Uracha anomalies: ultrasonography and management. J Pediatr Surg 38: 1203-1207. Link: https://bit.ly/3qbWhQL

5. Matsui F, Matsumoto F, Shimada K (2007) Prenatally diagnosed patent urachus with bladder prolapse. J Pediatr Surg 42: e7-10. Link: https://bit.ly/371z8zz

6. Lugo B, McNulty J, Emil S (2006) Bladder prolapse through a patent urachus: fetal and neonatal features. J Pediatr Surg 41: e5-e7. Link: https://bit.ly/2Ne1kBR

7. Yeats M, Pinch L (2003) Patent urachus with bladder eversion. J Pediatr Surg 38: e12-13. Link: https://bit.ly/3d19Qir

8. Riddell JV, Houle AM, Franc-Guimond J, Barrieras D (2015) Prenatal vesicoallantoic cyst outcome - a spectrum from patent urachus to bladder extrophy. Prenat Diagn 35: 1342-1346. Link: https://bit.ly/3jF4RoB

9. Srisupundit K, Mahawong P, Charoenratana Ch, Tongsong T (2018) Prolapsed bladder following rupture of patent urachal cyst, mimicking bladder extrophy: a case report and literature review. J Med Ultrason 45: 529-523. Link: https://bit.ly/3jFtxOA

10. Umeda S, Usui N, Kanagawa T, Yamsamich T, Nara K, et al. (2016) Prenata and postnatal clinical course of an urachus identified as as allantoic cyst in the umbilical cord. Eur J Pediatr Surg 26: 200-202. Link: https://bit.ly/3qaqkbr

11. Rasteiro C, Ramalho C, Loureiro T, PereirAJ, Matias A (2013) Bladder empting into an umbilical cord cyst: prenatal sonographic sign of allantoic cyts with patent urachus. Ultrasound Obstet Gynecol 42: 238-239. Link: https://bit.ly/3rNyB5T

12. Weichert J, Chiriac A, Kaiser M, Thorns C, Axt-Fliedner R (2009) Prenatal management of an allantoic cyst with patent urachus. Arch Gynecol Obstet 280: 321-323. Link: https://bit.ly/20mtevL

13. Fuchs F, Picone O, Levaillant JM, Mabille M, Mas AE, et al. (2008) Prenatal diagnosis of a patent urachus cyst with the use of 2D, 3D, 4 D ultrasound and fetal magnetic resonance imaging. Fetal Diagn Ther 24: 444-447. Link: https://bit.ly/3jBRi9w

14. Bunch PT, Kline-Fath BM, Imhoff SC, Calvo-Garcia MA, Crombleholme TM, et al. (2006) Allantoic cyst: a prenatal clue to patent urachus. Pediatr Radiol 36 : 1090-1095. Link: https://bit.ly/3jCl10B 
15. Raga F, Bonilla-Musoles F, Castillo JC (2012) SonoAVC: a new tool in early diagnosis of patent urachus with bladder prolapse. Ultrasound Obstet Gynecol 39: 241-242. Link: https://bit.ly/3tLaQgo
16. Thambi Dorai CR (2000) Umbilical evagination of the bladder with omphalocele minor. Pediatr Surg Int 16: 128-129. Link: https://bit.ly/3jE6flr
Discover a bigger Impact and Visibility of your article publication with

Peertechz Publications

\section{Highlights}

* Signatory publisher of ORCID

* Signatory Publisher of DORA (San Francisco Declaration on Research Assessment)

* Articles archived in worlds' renowned service providers such as Portico, CNKI, AGRIS, TDNet, Base (Bielefeld University Library), CrossRef, Scilit, J-Gate etc.

* Journals indexed in ICMJE, SHERPA/ROMEO, Google Scholar etc.

* OAI-PMH (Open Archives Initiative Protocol for Metadata Harvesting)

* Dedicated Editorial Board for every journal

* Accurate and rapid peer-review process

* Increased citations of published articles through promotions

* Reduced timeline for article publication

Submit your articles and experience a new surge in publication services (https://www.peertechz.com/submission).

Peertechz journals wishes everlasting success in your every endeavours. distribution, and reproduction in any medium, provided the original author and source are credited.

Citation: Warchol S, Slomska S, Roszkowski T, Dudek-Warchol T (2021) Prenatally diagnosed patent urachus with bladder prolapse: Case Report and review of the literature. Arch Urol Res 5(1): 006-009. DOI: https://dx.doi.org/10.17352/aur.000029 